\title{
Combined abiraterone acetate plus prednisone, salvage prostate bed radiotherapy and LH-RH agonists (CARLHA-GEP12) in biochemically-relapsing prostate cancer patients following prostatectomy: A phase I study of the GETUG/GEP
}

\author{
Stéphane Supiot ${ }^{1}$, Loic Campion ${ }^{1}$, Pascal Pommier ${ }^{2}$, Mélanie Dore ${ }^{1}$, Clément \\ Palpacuer ${ }^{1}$, Séverine Racadot ${ }^{2}$, Emmanuel Rio ${ }^{1}$, Gérard A. Milano ${ }^{3}$, Céline Mahier - \\ Ait Oukhatar ${ }^{4}$ and Christian Carrie ${ }^{2}$

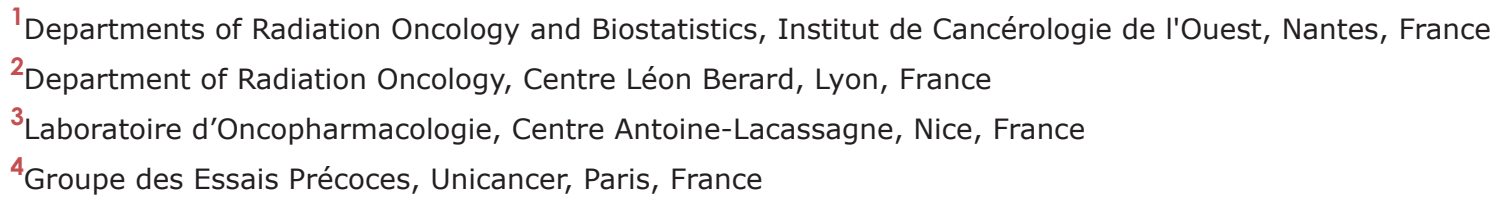

\section{ABSTRACT}

Background: To establish the maximum tolerated dose of abiraterone acetate plus prednisone (AA) combined with salvage radiotherapy (SRT) and goserelin in a phase 1 study in men with rising PSA following radical prostatectomy.

Methods: AA was given during one month before SRT at 1000 mg PO once daily, then $750 \mathrm{mg}$ (Dose Level 1, DL1) or $1000 \mathrm{mg}$ (DL2) during 5 months combined with 6-months goserelin by injection on the first day of irradiation (scheme NEO) or one month before starting SRT (scheme CONCO).

Results: In scheme NEO at DL1, 2/9 patients did not achieve castration levels of testosterone. 4/9 patients (44\%) presented with grade 3 liver enzyme elevation. In scheme CONCO testosterone dropped to undetectable levels. At DL1, 6 patients were recruited, with no dose limiting toxicities. At DL2, 2/3 patients presented with grade 3 liver enzyme elevation occurring during SRT.

Conclusions: When AA was administered without goserilin, only $78 \%$ achieved castration levels. AA combined with SRT and goserilin did not increase pelvic toxicity, but lead to an unsuspected high frequency of grade 3 liver toxicity. The phase II recommended dose of AA combined to goserelin and SRT is $750 \mathrm{mg}$.

\section{INTRODUCTION}

Despite adequate prostatectomy, up to $50 \%$ of localized prostate cancer patients may relapse biochemically [1]. As soon as the prostate specific antigen (PSA) is confirmed above $0.2 \mathrm{ng} / \mathrm{ml}$, these patients are routinely offered salvage prostate bed radiotherapy, which achieves a biochemical control rate of $60 \%$ at 5 years [2]. Two studies showed that adding hormone therapy (HT) to salvage prostate bed radiotherapy was able to significantly increase biochemical relapse-free survival to
$80 \%$ at 5 years [2] and increase overall survival at 12 years [3]. Combined HT and salvage radiotherapy can now be considered as standard of care in biochemically-relapsing prostate cancer patients.

To increase the systemic efficacy of HT, novel androgen-receptor (AR) signalling targeted agents have been developed [4]. Abiraterone acetate is an orally administered small molecule that irreversibly inhibits CYP17, a rate-limiting enzyme in androgen biosynthesis, and blocks the synthesis of androgens in the testes, adrenal glands and prostate [5]. The abiraterone metabolite $\Delta(4)$ - 
Table 1: Patients characteristics

\begin{tabular}{lccc}
\hline & NEO & CONCO & Total \\
\hline Number of patients & 9 & 9 & 18 \\
Median age (range) & 57 & 66 & 65 \\
Median PSA (ng/ml; range) & $0.29(0.21-0.8)$ & 5 & $0.43(0.21-1.48)$ \\
pT2 & 7 & $26-1.48)$ & 12 \\
pT3a & 0 & 2 & 4 \\
pT3b & 2 & 5 & 10 \\
Positive margins & 5 & 6 & 11 \\
Gleason score 7 (3+4) & 5 & 2 & 6 \\
Gleason score 7 (4+3) & 4 & 1 & $7(2-27)$ \\
Gleason score 9 (4+5) & 0 & $8(2-13)$ & \\
Median PSA doubling time (months; range) & $6(2-27)$ & & \\
\hline
\end{tabular}

abiraterone is also able to directly block the androgen receptor signalling pathways [6]. Abiraterone acetate plus prednisone is approved for the treatment of metastatic castration resistant $[7,8]$ and hormone-sensitive $[9,10]$ prostate cancer.

As there is no prospective data on the combination of abiraterone acetate plus prednisone and salvage prostate bed radiotherapy, the aim of this study was to further evaluate the safety profile of abiraterone acetate plus prednisone in patients with prostate cancer who are biochemically relapsing after surgery and undergo salvage radiotherapy with 6-months LH-RH agonist. We hypothesized that the toxicity profile of both treatments should not potentiate each other.

The CYP17A1 gene presents numerous single nucleotide polymorphisms (SNPs), whose frequencies of rare alleles are at least $12 \%$. Their functional impact has been suggested for nine of them, which were linked either to the risk of developing prostate cancer or to survival of prostate cancer patients [11]. So far, no study has examined the links between these polymorphisms and the effects of a CYP17A1 inhibitor. Also, relationships with the efficacy of androgen deprivation therapy have recently been reported for SNPs of genes involved in the membranetransport testosterone and dehydroepiandrosterone, namely SLCO2B1 and SLCO1B3 [12-14]. The present study proposed an original approach in order to highlight a relationship between abiraterone acetate plus prednisone activity and patient's genetic profile.

\section{RESULTS}

\section{Patient population}

Between 12/2012, and 01/2016, 9 and then 9 additional patients were treated in scheme NEO and
CONCO respectively (Table 1). 8 out of 9 patients treated in the scheme NEO were evaluable for DLT assessment, while 9/9 were evaluable for DLT in the scheme CONCO. At least one risk factor of relapse following salvage radiohormonotherapy $(\mathrm{PSA}>0.5 \mathrm{ng} / \mathrm{ml}$; $\mathrm{PDA} \mathrm{DT}<7$ months; negative surgical margins [2]) was found in most patients $(7 / 9$ in scheme $\mathrm{NEO}$ and $8 / 9$ in scheme CONCO respectively).

\section{Testosterone and $\mathrm{LH}$ serum levels}

When abiraterone acetate $(1000 \mathrm{mg})$ plus prednisone was administered without goserelin (scheme NEO), testosterone levels dropped to less than $50 \mathrm{ng} / \mathrm{dl}$ (castration levels) after a median time of 10 days (Figure 1B). However, 2/9 (22\%) patients did not achieve castration levels of testosterone. After one month, goserelin was added and subsequently all patients achieved undetectable testosterone levels. Median LH levels increased to 10.4 and $12.5 \mathrm{IU} / 1$ at day 10 and 20 respectively in all patients (Figure 1C). CYP17A1, SLCO2B1, SLCO2B3, CYP3A4 CYP3A5 polymorphism was determined in all patients (Supplementary Table 1) but did not correlate with a lack of castration on day 27.

When abiraterone acetate plus prednisone was administered with concurrent goserelin (scheme CONCO), testosterone levels dropped to undetectable levels at day 6 , while median LH levels decreased to 6.1 and $1.7 \mathrm{IU} / 1$ at day 10 and 20 respectively (Figure $1 \mathrm{D} \& 1 \mathrm{E}$ ). All patients except 3 with a short follow-up (12 months) recovered testosterone levels above castration levels $(>50 \mathrm{ng} / \mathrm{dl})$.

\section{Toxicity analysis}

We started with the NEO scheme at DL1 (Table 2). Abiraterone acetate plus prednisone combined with LH- 
A

\begin{tabular}{c|cccc} 
& w1 & w5 & w11 & w27 \\
NEO & $\begin{array}{c}\text { Abi } 1000 \\
+ \text { pred }\end{array}$ & Abiraterone increasing dose + prednisone & w32 \\
\hline & \multicolumn{2}{c}{ Goserilin q 3m during 6 months }
\end{tabular}

\section{Prostate bed RT}

\begin{tabular}{c|c|c|c|} 
CONCO & $\begin{array}{c}\text { Abi } 1000 \\
+ \text { pred }\end{array}$ & Abiraterone increasing dose + prednisone \\
\hline & \multicolumn{2}{c}{ Goserilin q $3 \mathrm{~m}$ during 6 months }
\end{tabular}

\section{Prostate bed RT}

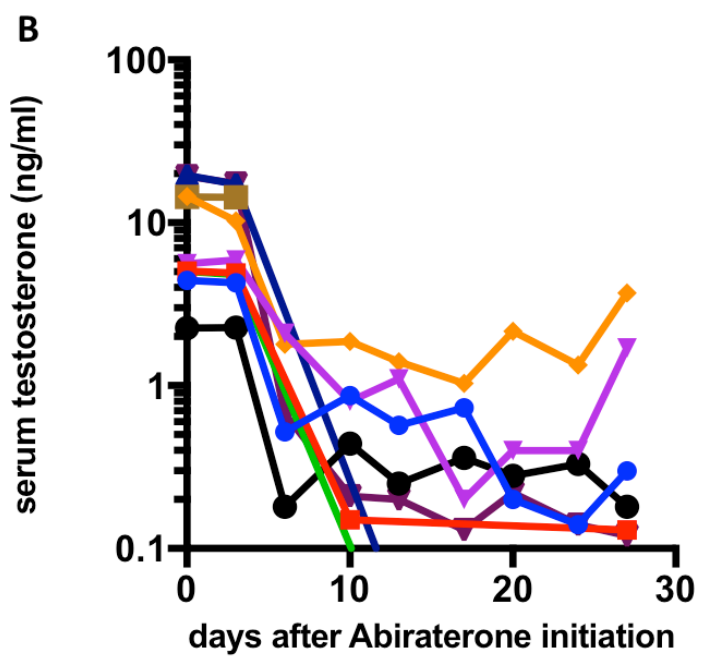

C

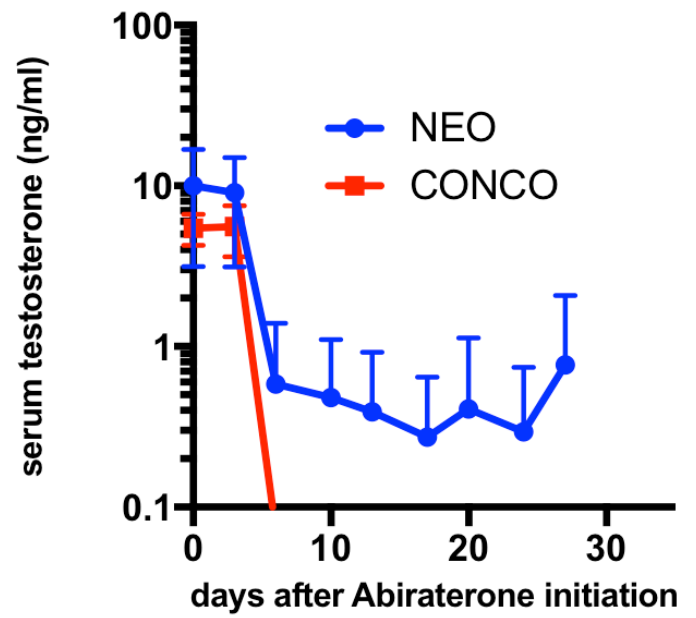

D

E
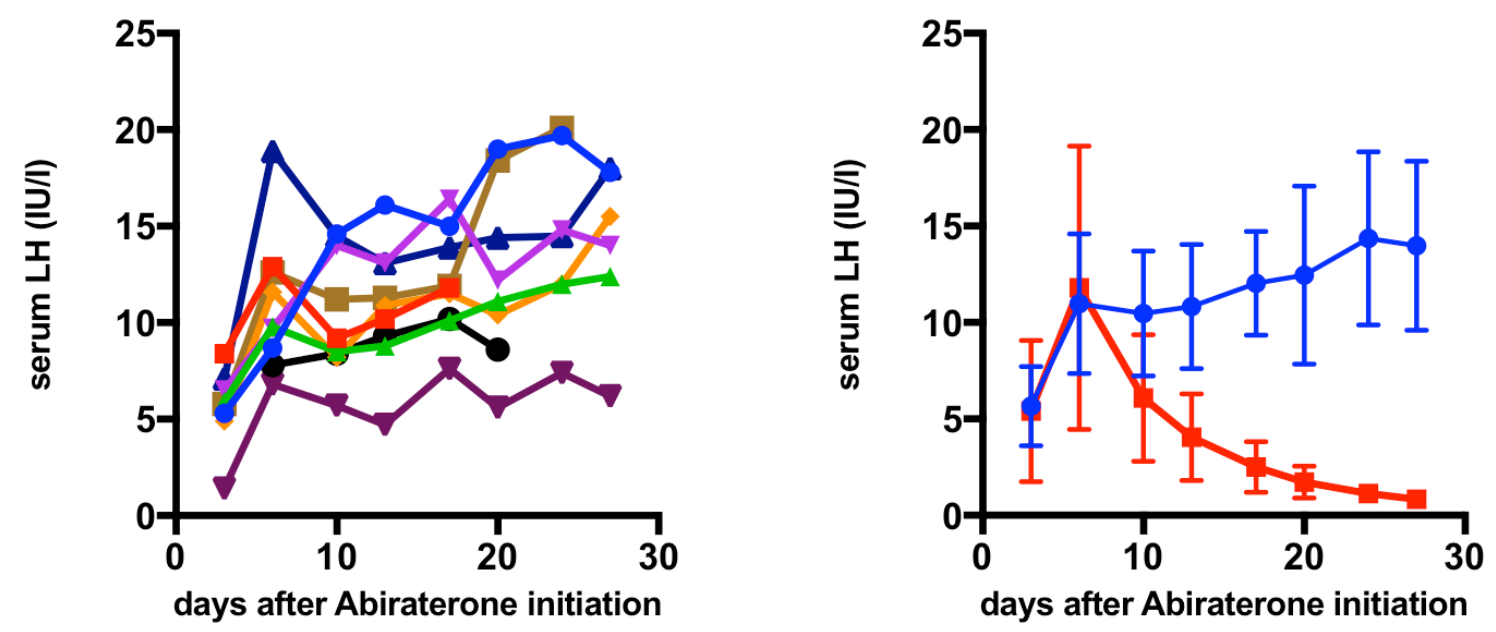

Figure 1: Testosterone and LH levels following different mode of administration of abiraterone. (A) schematic representation of the NEO and CONCO schemes; (B) serum testosterone levels following neo adjuvant (NEO) abiraterone administration in all 9 patients; (C) serum LH levels following neo adjuvant (NEO) abiraterone administration in all 9 patients; (D) serum testosterone levels following neo adjuvant (NEO) or concurrent (CONCO) abiraterone administration (mean+/- SD); (E) serum LH levels following neo adjuvant (NEO) or concurrent (CONCO) abiraterone administration (mean+/- SD). 
Table 2: Dose levels and dose-limiting toxicities

\begin{tabular}{|c|c|c|c|c|c|c|}
\hline Scheme & DL & Patients & $\begin{array}{l}\text { Abiraterone acetate dose } \\
\qquad(\mathrm{mg} / \mathrm{d})\end{array}$ & $\begin{array}{c}\text { DL escalating } \\
\text { order }\end{array}$ & DLT & Description \\
\hline NEO & DL1 & $9\left(1 \mathrm{NE}^{*}\right)$ & 750 & 1 & 3 & $\begin{array}{c}3 \text { patients with G3 } \\
\text { ALT/AST liver enzyme } \\
\text { elevation }\end{array}$ \\
\hline $\mathrm{CONCO}$ & DL1 & $3+3$ & 750 & $\begin{array}{l}2 \\
4\end{array}$ & 0 & \\
\hline CONCO & DL2 & 3 & 1000 & 3 & 2 & $\begin{array}{c}2 \text { patients with G3 } \\
\text { ALT/AST liver enzyme } \\
\text { elevation }\end{array}$ \\
\hline
\end{tabular}

${ }^{*}$ Non evaluable for DLT (treatment stopped before DLT evaluation period due to grade 3 ALT/AST liver enzyme elevation).

RH agonists and radiotherapy did not lead to in-field grade 3 bladder or rectum toxicity. One patient was hospitalized with grade 3 renal insufficiency following grade 3 febrile $\left(39.3^{\circ} \mathrm{C}\right)$ diarrhea and vomiting that resolved within 2 days with IV antibiotics during the $5^{\text {th }}$ week of radiotherapy (SRT at 52 Gy). CRP was highly elevated $(237 \mathrm{mg} / \mathrm{ml})$. Abiraterone acetate plus prednisone was continued during this episode, but radiotherapy was discontinued for 2 days. This toxicity was considered as infectious and unrelated to the treatment.

At dose level 1, 4/9 patients (44\% 95\% CI [13.778.8]) presented with grade 3 liver function tests elevation (ALT and/or AST $>5 \times \mathrm{ULN}$ ), occurring prior to RT or during SRT at $8 \mathrm{~Gy}, 36 \mathrm{~Gy}$ and $54 \mathrm{~Gy}$. The 3 cases of liver toxicities occurred during SRT in 3 out of 6 patients evaluable for DLT were considered as DLT (Table 3). A septic shock following lung infection occurred in a patient with a past history of bronchiectasis 3 months after completion of radiotherapy. This toxicity was considered as unrelated to the treatment. No other grade 3 out-of-field toxicity was reported.

We hypothesized that this unexpected liver toxicity was related to the lack of concurrent LH-RH agonist. Therefore, we decided to modify LH-RH administration (scheme CONCO) and recruited 9 more patients. Grade 3 urinary incontinence was reported in one patient. No grade 3 rectal toxicity was reported.

At DL1 (750 mg abiraterone acetate during radiotherapy), no grade 3 out-of-field toxicity was reported, nor any DLT, on 3 out of 3 patients. The dose was escalated to DL2, where $2 / 3$ patients presented a DLT with grade 3 liver function tests elevation occurring during SRT at 14 Gy and 24 Gy and the third patient presented a grade 2 liver function tests elevation. To confirm the MTD, up to 6 patients were recruited at DL1. Among these 3 supplementary patients, no liver toxicity, nor any other DLT was reported. We concluded that the MTD of abiraterone acetate + prednisone + LH-RH agonist + salvage pelvic radiotherapy was $750 \mathrm{mg}$ during the course of radiotherapy. CYP17A1, SLCO2B1, SLCO2B3, CYP3A4 CYP3A5 polymorphism was determined in all patients (Supplementary Table 1) but did not correlate with the occurrence of liver toxicity. At DL1, only one grade 3 out-of-field toxicity (lymphopenia) was reported. No grade 3 hypokalemia, cardiac disorders or fluid retention/ edema was reported.

\section{Efficacy}

After a median follow-up of 30.6 months (range $12-48$ ), biochemical relapse-free survival was $89 \%$ (one patient with a PSA of $0.7 \mathrm{ng} / \mathrm{ml}$ at 36 months in the NEO group DL1 without liver toxicity) (Supplementary Figure 2).

\section{DISCUSSION}

Radiotherapy combined with hormone therapy is a standard of care for prostate cancer at many stages [15], but limited information is available regarding the combination of next generation androgen-receptor signaling targeted drugs and radiohormonotherapy [16]. This phase 1 study is the first to analyze the toxicity of abiraterone acetate plus prednisone combined with prostate bed radiotherapy and LH-RH agonists comparing a neoadjuvant and a concurrent scheme of administration of abiraterone acetate plus prednisone. Full dose abiraterone acetate (1000 mg) plus prednisone had never been previously evaluated without LH-RH agonists. This phase 1 study shows that $22 \%$ of patients did not achieve castration levels when abiraterone acetate plus prednisone was administered without LH-RH agonists, precluding from the routine use of abiraterone acetate plus prednisone without LH-RH agonists. When combined with prostate bed radiotherapy and $\mathrm{LH}-\mathrm{RH}$ agonists, abiraterone acetate plus prednisone did not increase bladder or intestine toxicity. Surprisingly, the combined treatment led to an unsuspected high frequency of grade 3 liver toxicity. The 
Table 3: Adverse events Only the highest grade of toxicity is reported

\begin{tabular}{|c|c|c|c|c|c|c|c|c|c|}
\hline Scheme & NEO & & & CONCO & & & CONCO & & \\
\hline Abi Ac dose during RT & $750 \mathrm{mg}$ & & & $750 \mathrm{mg}$ & & & $1000 \mathrm{mg}$ & & \\
\hline Number of patients & 9 & & & 6 & & & 3 & & \\
\hline Toxicity grade & 1 & 2 & 3 & 1 & 2 & 3 & 1 & 2 & 3 \\
\hline \multicolumn{10}{|l|}{ In-field side-effects } \\
\hline \multicolumn{10}{|l|}{ Bowel toxicity } \\
\hline Diarrhea & & & & & & & 1 & & \\
\hline Constipation & & & & 1 & & & 1 & & \\
\hline $\begin{array}{l}\text { Excessive rectal } \\
\text { mucus }\end{array}$ & 1 & & & & & & & & \\
\hline Rectal bleeding & 2 & & & 3 & & & & & \\
\hline Rectal urgency & 1 & & & & 1 & & & & \\
\hline Anorectal pain & 3 & & & 4 & & & & & \\
\hline Abdominal pain & & & & 1 & & & & & \\
\hline $\begin{array}{l}\text { Number of patients with } \\
\text { bowel toxicities }\end{array}$ & 5 & 0 & 0 & 6 & 1 & 0 & 1 & 0 & 0 \\
\hline \multicolumn{10}{|l|}{ Bladder toxicity } \\
\hline Bladder urgency & 3 & & & & & & & & \\
\hline Urine incontinence & 3 & 1 & & 2 & 1 & 1 & 1 & & \\
\hline Nocturia & 1 & & & & & & 1 & & \\
\hline Pollakiuria & 3 & 1 & & 3 & & & 1 & 1 & \\
\hline Bladder pain & & & & 1 & & & & & \\
\hline Dysuria & 1 & & & & & & & & \\
\hline $\begin{array}{l}\text { Number of patients with } \\
\text { bladder toxicities }\end{array}$ & 7 & 1 & 0 & 3 & 1 & 1 & 2 & 1 & 0 \\
\hline
\end{tabular}

Out-of-field side-effects

Liver

Increased ALT

Increased AST

Increased bilirubin

Number of patients with liver toxicities

Cardio-vascular

Arterial

hypertension

\begin{abstract}
Bradycardia
Tachycardia
\end{abstract}

Phlebitis

Number of patients with cardio-vascular toxicities

Other treatmentrelated toxicities

Asthenia
Hot flashes

3

3

4

1

1

2

1

6 


\begin{tabular}{|c|c|c|c|c|c|c|c|c|c|}
\hline Scheme & NEO & & & CONCO & & & CONCO & & \\
\hline Abi Ac dose during RT & $750 \mathrm{mg}$ & & & $750 \mathrm{mg}$ & & & $1000 \mathrm{mg}$ & & \\
\hline Number of patients & 9 & & & 6 & & & 3 & & \\
\hline Toxicity grade & 1 & 2 & 3 & 1 & 2 & 3 & 1 & 2 & 3 \\
\hline Headaches & 2 & & & & & & & & \\
\hline Depression & 1 & 1 & & & & & & & \\
\hline Breast pain & 1 & & & & & & & & \\
\hline $\begin{array}{l}\text { Muscle pain or } \\
\text { muscle cramps }\end{array}$ & 2 & & & & & & & & \\
\hline Anemia & 1 & & & & & & & & \\
\hline Hypokalemia & & 1 & & 1 & & & & & \\
\hline Leucopenia & 1 & & & & & & & & \\
\hline Lymphopenia & 1 & & 1 & 1 & 4 & 1 & 1 & & \\
\hline Monopenia & 1 & & & & & & & & \\
\hline Thrombopenia & 1 & & & 1 & & & & & \\
\hline $\begin{array}{l}\text { Number of patients with } \\
\text { other treatment-related } \\
\text { toxicities }\end{array}$ & 6 & 4 & 1 & 5 & 5 & 1 & 2 & 0 & 0 \\
\hline $\begin{array}{l}\text { Total number of } \\
\text { patients with toxicities }\end{array}$ & 9 & 6 & 5 & 6 & 6 & 2 & 3 & 3 & 2 \\
\hline
\end{tabular}

Adverse events considered not related to treatment were: grade 4 septic shock following lung infection in a patient with bronchiectasis $(\mathrm{n}=1)$, grade 3 renal insufficiency in a patient with grade 3 febrile diarrhea $(\mathrm{n}=1)$, grade 2 eczema $(\mathrm{n}=1)$, grade 1 skin dryness $(n=1)$, grade 1 mycosis $(n=1)$, grade 1 laryngitis $(n=1)$, grade 1 tinnitus $(n=1)$, grade 1 osteopenia $(n=1)$, grade 2 painful kidney lithiasis $(n=1)$, grade 1 lumbar pain $(n=1)$, grade 1 dyspepsia $(n=2)$, grade 1 conjunctival haemorrhage $(\mathrm{n}=1)$.

P2RD of abiraterone acetate plus prednisone combined to goserelin and SRT was therefore set to $750 \mathrm{mg}$ using a concurrent scheme of administration.

The effects of abiraterone acetate plus prednisone without LH-RH agonists in prostate cancer patients is not well documented. The only phase 1 study that evaluated the effects of abiraterone acetate plus prednisone without LH-RH agonists was limited to a short treatment duration (12 days) and a dose lower ( $800 \mathrm{mg}$ ) than the currently recommended dose $(1000 \mathrm{mg})$ [5]. When abiraterone acetate plus prednisone was administered during one month before starting LH-RH agonists and radiotherapy in 9 patients, only $7 / 9(78 \%)$ of patients achieved castration levels of testosterone. This lack of castration is probably due to the feedback increased LH levels that LH-RH agonists abrogate. The interpatient variability of abiraterone pharmacokinetics is quite high. The mode of administration of abiraterone acetate was similar in all patients. Abiraterone acetate plus prednisone's efficacy might be affected by CYP17A1 polymorphism $[17,18]$, but no specific profile could be determined in the 2 patients who did not achieve castration levels of testosterone. In general, the pharmacogenetics translational study was inconclusive. It covered CYP17A1-linked SNPs and SNPs of genes controlling testosterone and dehydroepiandrosterone transport gene-linked SNPs. The reason for this negative result may be due to the limited number cases of the present study. Altogether, these results suggest that abiraterone acetate plus prednisone should not be administered without LH-RH agonists.

Abiraterone acetate plus prednisone treatment did not increase the pelvic toxicity of radiotherapy. Toxicity of pelvic radiotherapy is usually limited to the bladder or the intestine with a rate of grade 3 acute toxicity of less than $5 \%$. Combined abiraterone acetate plus prednisone, salvage prostate bed radiotherapy and LH-RH agonists did not acutely damage the bladder or the intestine. Only one patient $(6.2 \%)$ suffered from grade 3 acute bladder incontinence during the course of radiotherapy, which can be related to both previous prostatectomy and radiotherapy. Only one patient suffered from grade 3 diarrhea complicated by renal insufficiency, but it was considered as unrelated to the treatments because the patient was febrile and the diarrhea resolved with IV antibiotics. Abiraterone can induce hypokalemia secondary to hyperaldosteronism and radiotherapyinduced diarrhea could increase this risk. No hypokalemia was reported during the combined therapy. This lack of increased pelvic toxicity is similar to another study in locally advanced cancer where abiraterone acetate plus 
prednisone was combined with LH-RH agonists and prostate and pelvic lymphnodes radiotherapy [19].

The P2RD of abiraterone acetate plus prednisone combined with prostate bed radiotherapy and LH-RH agonists is $750 \mathrm{mg}$ (DL1) since this combination at dose level 2 lead to an unsuspected high frequency of grade 3 liver toxicity $(6 / 18,33 \% 95 \%$ CI [13.3-59.0] considering all groups; 2/3, 66\% 95\%CI [9.4-99.2] considering only patients in the CONCO group DL2). This liver toxicity when combined with radiotherapy is much higher than previous reports on abiraterone acetate plus prednisone without radiotherapy in the localized or metastatic setting where grade 3 liver toxicity was noted in only $3-10 \%$ of patients $[7,8,19,20]$. No direct comparison can be done between large randomized phase 3 studies and our small phase 1 series, and the increased liver toxicity in our phase 1 study may be due to the small numbers of patients recruited. However, our 33.3\% (6/18) rate of liver function tests elevation seems much higher than a rate of 3.4\% (27/791; bilateral Fisher test, $\mathrm{P}<10^{-6}$; Supplementary Table 2). The cause of hepatic injury from abiraterone is unknown (https://livertox.nlm.nih.gov//Abiraterone. $\mathrm{htm})$. Liver toxicity was more frequent at higher doses with $2 / 3$ patients in the DL2 cohort and only 4/15 in the DL1 patients. In our study, no patient-related risk factor (alcohol consumption, viral infection, concurrent medication) or other drug-related parameters (timing of administration, batch number) could explain this toxicity. Liver toxicity of abiraterone acetate plus prednisone may relate to its mechanism of action in inhibition of CYP17. Polymorphism in CYP17 may be involved in determining susceptibility of tamoxifen-induced hepatic steatosis [21]. We could not find a correlation between CYP17 polymorphism and abiraterone acetate plus prednisoneinduced liver function tests elevation. Our results are in contradiction with another phase 1 study where abiraterone acetate plus prednisone was combined with LH-RH agonists and prostate and pelvic lymphnodes radiotherapy that showed that only $9 \%$ of patients presented grade 3 liver toxicity [19]. The main differences between the 2 studies are (1) the concurrent use of abiraterone acetate plus prednisone and LH-RH agonists, (2) the longer duration (12 weeks) of neoadjuvant abiraterone acetate plus prednisone, (3) the larger radiotherapy fields including prostate and pelvic lymphnodes in Cho et al. None of these differences can easily explain an increased liver toxicity in our study.

To explain this liver toxicity, we can raise two hypotheses. On the one hand, grade 3 liver toxicity affected more patients in the NEO group (4/9, 44\%; 95\% CI [13.7-78.8]) than in the CONCO group (2/9 $22.2 \%, 95 \%$ CI [2.81-60.00] only at dose level 2). From this observation, we can hypothesize that abiraterone pharmacokinetics might be affected by castration. Indeed, castration using LH-RH agonists increases clearance of docetaxel, thereby reducing its toxicity on neutrophils
[22]. To test this hypothesis, we will monitor abiraterone pharmacokinetics in the phase 2 study. On the other hand, liver enzymes raised to grade 3 during the course of radiotherapy in 8/9 patients with a grade 3 liver toxicity. We can also hypothesize that systemic effects of radiotherapy might affect the liver toxicity of abiraterone. The release of inflammatory cytokines can mediate radiation toxicity [23]. In mice, pelvic radiotherapy increased TNF-alpha production [24] and TNF-alpha was shown to induce liver injury [25]. In patients, IFN- $\gamma$ and IL-6 significantly increased during prostate IMRT [26] and Interferon-gamma exacerbates liver damage [27] and high levels of IL-6 are found in patients with liver function tests elevation [28]. To test this hypothesis, cytokines levels will be measured during the phase 2 study.

Although restricted to a limited number of patients and a short follow-up, biochemical relapse-free survival (89\%) is encouraging with only one patient with a PSA above $0.10 \mathrm{ng} / \mathrm{ml}$ after a median follow-up of 3 years, despite a vast majority of patients presented at least one risk factor of relapse following salvage radiohormonotherapy. Recent phase 3 studies showed that hormone therapy combined with prostate bed radiotherapy could increase biochemical-relapse free [2] or overall survival [3] in patients with a detectable PSA following radical prostatectomy. Since most relapse following prostate bed radiotherapy occur outside the prostate bed [29], major improvements should be achieved by adding systemic therapy such as novel androgen receptor signaling targeted agents. A phase 2 study with combined abiraterone acetate plus prednisone, salvage prostate bed radiotherapy and LH-RH agonists in a larger patient population is ongoing.

\section{PATIENTS AND METHODS}

\section{Patients}

We conducted a multicenter, prospective, openlabel phase Ib study evaluating the efficacy and safety of a 6-month abiraterone acetate plus prednisone plus LH-RH agonist combined with prostate-bed radiotherapy in the Radiotherapy Departments of the Institut de Cancérologie de l'Ouest, Nantes, and Centre Léon Bérard, Lyon, both in France.

Eligible patients were men aged 18 years or older, with histologically confirmed adenocarcinoma of the prostate, stage pT2, pT3, and pT4a (bladder neck involvement only), and pN0, who had received radical prostatectomy. Eligible patients had PSA concentrations of less than $0.1 \mu \mathrm{g} / \mathrm{L}$ for at least 6 months after surgery, which then began to rise (to between $0.2 \mu \mathrm{g} / \mathrm{L}$ and $<2$ $\mu \mathrm{g} / \mathrm{L}$, as confirmed by two consecutive tests) without evidence of clinical disease (total bone scan and pelvic CT scan). Other inclusion criteria were a performance status of $0-1$, serum potassium $\geq 3.5 \mathrm{mmol} / 1$ in the 72 
hours before first dose of abiraterone, serum creatinine $<$ $1.5 \times$ ULN or a calculated creatinine clearance $\geq 60 \mathrm{~mL} /$ min, serum bilirubin $<1.5 \mathrm{x}$ ULN (except for patients with documented Gilbert's disease), AST and/or ALT $<2.5 \mathrm{x}$ ULN.

Patients were excluded if: they had undergone previous androgen deprivation therapy or pelvic radiotherapy, the initial status at the time of surgery was $\mathrm{pN} 1$, histology findings showed cancer other than adenocarcinoma, the patient had another invasive cancer in the previous 5 years, another antineoplastic treatment was in progress, previous hormone therapy including prior therapy with ketoconazole or a CYP17 inhibitor(s) for prostate cancer had been administered, and in case of uncontrolled hypertension (defined as systolic BP $\geq$ $140 \mathrm{mmHg}$ or diastolic BP $\geq 90 \mathrm{mmHg}$ ). Patients with a history of hypertension were allowed provided blood pressure was controlled by anti-hypertensive therapy. Patients with active or symptomatic viral hepatitis or chronic liver disease, severe and moderate hepatic impairment (Child-Pugh class B and C), and patients being treated within the last 14 days prior to inclusion with drugs recognized as being strong inhibitors or inducers of the isoenzyme CYP3A4 (clarithromycin, ketoconazole, itraconazole, voriconazole, ritanovir,) or requiring those treatments during the study were also excluded. Patients with known hypersensitivity to any of the study drugs or excipients, galactosemia, glucose-galactose malabsorption or lactase deficiency, with severe and/or uncontrolled medical disease which could compromise participation in the study, such as, but not limited to clinically significant heart disease as evidenced by myocardial infarction, or arterial thrombotic events in the past 6 months, severe or unstable angina, or New York Heart Association (NYHA) Class III or IV heart disease or cardiac ejection fraction measurement of $<50 \%$ at baseline were also excluded.

\section{Objectives}

The objective of this phase 1 study was to determine the maximum tolerated dose (MTD) and the phase II recommended dose (P2RD) of abiraterone acetate plus prednisone combined with radiotherapy and LH-RH agonist treatment in patients with biochemical relapse from prostate cancer following surgery. Exploratory objectives aimed to evaluate potential biomarkers of abiraterone acetate plus prednisone treatment toxicity, and to perform testosterone and LH serum levels assays.

\section{Toxicity assessment}

Toxicities were assessed weekly during the DLT evaluation period and at every visit through a clinical assessment, laboratory examinations and an ECG every 3 months. The DLT evaluation period covered 11 weeks starting from the radiotherapy initiation. Toxicities were scored according to National Cancer Institute (NCI) Common Terminology Criteria for Adverse Events (CTCAE), version 4.0.

\section{Radiotherapy}

All patients underwent radiotherapy starting on day 30 after abiraterone acetate plus prednisone initiation. A total dose of 66 Gy in 33 fractions (5 a week) was delivered to the prostate bed using Intensity Modulated Radiation Therapy. Clinical target volume (CTV) limits were based on the guidelines of the RTOG consensus guidelines [30]. Planning target volume (PTV) was obtained by adjunction of a 7-mm margin in all directions. The following limits were set: less than $50 \%$ and $100 \%$ of the rectal wall was to receive 60 Gy or 50 Gy respectively; less than $100 \%$ of the bladder wall was to receive $50 \mathrm{~Gy}$.

\section{Abiraterone acetate plus prednisone and LH-RH agonist}

During one month before initiating radiotherapy, abiraterone acetate was taken orally at the dose of 1000 $\mathrm{mg}$ /day (i.e. four tablets of $250 \mathrm{mg}$ once daily) plus prednisone $5 \mathrm{mg}$ twice daily. Then, abiraterone acetate and prednisone were administered in accordance to the doseescalation scheme (see below).

HT consisted of a 3-month depot preparation of goserelin administered subcutaneously in two injections separated by a three-month interval. Goserelin was initiated either with radiotherapy (scheme NEO), or concomitantly with abiraterone one month before starting radiotherapy (scheme CONCO) (Figure 1A).

\section{Dose-escalation scheme}

This dose range finding phase I study investigated the maximum tolerated dose (MTD) of abiraterone acetate plus prednisone in combination with prostate-bed radiotherapy and $\mathrm{LH}-\mathrm{RH}$ agonist, based on dose-limiting toxicities (DLT) occurrence using a 3x3 algorithm model (Supplementary Figure 1). After initiating radiotherapy, abiraterone acetate plus prednisone $5 \mathrm{mg}$ twice daily were taken orally according to a dose seeking procedure starting at $750 \mathrm{mg} /$ day (i.e., 3 tablets of abiraterone acetate $250 \mathrm{mg}$ once daily, DL1). If no DLT was observed during the 11week DLT evaluation period in the cohort of 3 patients, the next level was open (1000 mg; dose level 2). If one DLT out of three patients ( 1 DLT/3) was observed, that dose level was expanded to 6 patients. If two DLT, or more, were observed (i.e. $\geq 2$ DLTs / 3 or 2 DLTs / 6), this dose level was considered to have exceeded the MTD and the preceding dose level was expanded to 6 patients. Once the MTD was reached, it needed to be confirmed on a total of 6 patients. In case of non-pelvic DLT, abiraterone acetate was definitely withheld and corticoids gradually tapered. 
Any patient withdrawn before starting radiotherapy or during the DLT evaluation period for any other reason than a DLT was replaced by another patient.

\section{Pharmacogenomics}

We assessed testosterone and LH serum level variations weekly during one month after abiraterone acetate plus prednisone initiation in scheme NEO and $\mathrm{CONCO}$. We assessed 15 single-nucleotide polymorphisms (SNP) on 5 genes. CYP17A1 gene (allele frequency of the rare alleles $>12 \%$ ) potentially related to the pharmacogenomics of abiraterone (-34 $\mathrm{T}>\mathrm{C} \quad(\mathrm{rs} 743572), \quad-362 \quad \mathrm{~T}>\mathrm{C} \quad(\mathrm{rs} 2486758), \quad 35 \quad \mathrm{~T}>\mathrm{C}$ (rs1004467), $137 \mathrm{G}>\mathrm{A}$ (rs6162), $195 \mathrm{C}>\mathrm{A}(\mathrm{rs} 6163)$, $11994 \mathrm{C}>\mathrm{A}$ (rs4919683), $13871 \mathrm{~A}>\mathrm{G}$ (rs10883782), $15831 \mathrm{G}>\mathrm{T}(\mathrm{rs} 619824)$ and $1243+113 \mathrm{~T}>\mathrm{A}(\mathrm{rs} 10883783))$, CSLCO2B1 gene (rs1077858, rs12422149, rs1789693), SLCO1B3 gene (rs4149117), CYP3A4 gene (rs2740574) and CYP3A5 gene (rs776746) by Mass Array (iPlex chemistry from AGENA, San Diego, USA). DNA was extracted from blood on a Maxwell16 IVD extractor (purification kit AS1290, Promega, Wisconsin, USA). DNA was then analyzed by Mass Array. The first step of this analysis corresponds to an amplification of the region around the SNPs of interest, followed by a SAP treatment prior the final extend primer steps. The extension products were then dispensed onto a SpectroCHIP ${ }^{{ }^{{ }^{*}}}$ array with a nanodispenser RS100 (AGENA) and detected via MassARRAY MALDI-TOF mass spectrometry (MassARRAY Dx Analyzer 4, AGENA) and the mass spectra analyzed by the TyperAnalyzer software (4.0.26.75).”

\section{Statistical analysis}

The primary objective of this phase I study was to determine the MTD of abiraterone acetate plus prednisone combined with radiotherapy and LHRH agonist treatment in patients with biochemical relapse from prostate cancer following surgery. A dose-escalation scheme based on a $3+3$ algorithm model was planned (Supplementary Figure 1). The MTD was defined as the highest of the dose level associated with strictly less than 2 out of 3 or 6 patients presenting with a DLT. A DLT was defined as any treatment-related toxicity occurring over a 11-week period starting from radiotherapy initiation and ending 4 weeks after the radiotherapy termination. Toxicities occurring during the abiraterone acetate plus prednisone pretreatment period of 30 days were not considered as DLTs but were reported as adverse events. Toxicities were graded according to the National Cancer Institute Common Terminology Criteria (NCI CTC, version 4.0).

All patients who received any study agent were monitored for toxicity and included in the safety analysis. To be evaluable for DLT, a patient must either be observed for a full DLT evaluation period, (i.e. 11 weeks from the radiotherapy initiation) or have experienced a DLT.

Statistical analyses were performed with SAS statistical software, V9.4 (SAS Institute, Cary, NC, USA).

\section{CONCLUSIONS}

This study is the first to show that full dose abiraterone acetate $(1000 \mathrm{mg})$ plus prednisone $(5 \mathrm{mg}$ BID) without LH-RH agonists is not able to achieve a durable testosterone decrease at castration levels, due to LH feedback increase. The use of abiraterone acetate plus prednisone without LH-RH agonists is therefore not recommended. Moreover, this phase 1 study is the first to show that abiraterone acetate plus prednisone combined with prostate bed radiotherapy and LH-RH agonists does not increase bladder or intestine toxicity, but surprisingly leads to a frequent grade 3 ALT/AST liver enzyme elevation. The recommended dose of concurrent abiraterone acetate plus prednisone (5 mg BID), LH-RH agonists and prostate bed radiotherapy is $750 \mathrm{mg}$.

\section{ACKNOWLEDGMENTS}

We thank Dr Gwenaëlle Gravis and Dr Karim Fizazi for fruitful discussions regarding the project and the patients who participated to the study.

\section{CONFLICTS OF INTEREST}

This study was funded by Janssen.

\section{Editorial note}

This paper has been accepted based in part on peerreview conducted by another journal and the authors' response and revisions as well as expedited peer-review in Oncotarget.

\section{REFERENCES}

1. Thoms J, Goda JS, Zlotta AR, Fleshner NE, van der Kwast TH, Supiot S, Warde P, Bristow RG. Neoadjuvant radiotherapy for locally advanced and high-risk prostate cancer. Nat Rev Clin Oncol. 2011; 8:107-13. https://doi. org/10.1038/nrclinonc.2010.207.

2. Carrie C, Hasbini A, de Laroche G, Richaud P, Guerif S, Latorzeff I, Supiot S, Bosset M, Lagrange JL, Beckendorf V, Lesaunier F, Dubray B, Wagner JP, et al. Salvage radiotherapy with or without short-term hormone therapy for rising prostate-specific antigen concentration after radical prostatectomy (GETUG-AFU 16): a randomised, multicentre, open-label phase 3 trial. Lancet Oncol. 2016; 17:747-56. https://doi.org/10.1016/ S1470-2045(16)00111-X. 
3. Shipley WU, Seiferheld W, Lukka HR, Major PP, Heney NM, Grignon DJ, Sartor O, Patel MP, Bahary JP, Zietman AL, Pisansky TM, Zeitzer KL, Lawton CA, et al, and NRG Oncology RTOG. Radiation with or without Antiandrogen Therapy in Recurrent Prostate Cancer. N Engl J Med. 2017; 376:417-28. https://doi.org/10.1056/NEJMoa1607529.

4. Dal Pra A, Locke JA, Borst G, Supiot S, Bristow RG. Mechanistic Insights into Molecular Targeting and Combined Modality Therapy for Aggressive, Localized Prostate Cancer. Front Oncol. 2016; 6:24. https://doi. org/10.3389/fonc.2016.00024.

5. O’Donnell A, Judson I, Dowsett M, Raynaud F, Dearnaley D, Mason M, Harland S, Robbins A, Halbert G, Nutley B, Jarman M. Hormonal impact of the 17alpha-hydroxylase/ $\mathrm{C}(17,20)$-lyase inhibitor abiraterone acetate (CB7630) in patients with prostate cancer. Br J Cancer. 2004; 90:231725. https://doi.org/10.1038/sj.bjc.6601879.

6. Li Z, Bishop AC, Alyamani M, Garcia JA, Dreicer R, Bunch D, Liu J, Upadhyay SK, Auchus RJ, Sharifi N. Conversion of abiraterone to D4A drives anti-tumour activity in prostate cancer. Nature. 2015; 523:347-51. https://doi.org/10.1038/ nature14406.

7. de Bono JS, Logothetis CJ, Molina A, Fizazi K, North $\mathrm{S}$, Chu L, Chi KN, Jones RJ, Goodman OB Jr, Saad F, Staffurth JN, Mainwaring P, Harland S, et al, and COU-AA-301 Investigators. Abiraterone and increased survival in metastatic prostate cancer. N Engl J Med. 2011; 364:1995-2005. https://doi.org/10.1056/NEJMoa1014618.

8. Ryan CJ, Smith MR, de Bono JS, Molina A, Logothetis CJ, de Souza P, Fizazi K, Mainwaring P, Piulats JM, Ng S, Carles J, Mulders PF, Basch E, et al, and COU-AA-302 Investigators. Abiraterone in metastatic prostate cancer without previous chemotherapy. N Engl J Med. 2013; 368:138-48. https://doi.org/10.1056/NEJMoa1209096.

9. James ND, Spears MR, Sydes MR. Abiraterone in Metastatic Prostate Cancer. N Engl J Med. 2017; 377:169697. https://doi.org/10.1056/NEJMc1711029.

10. Fizazi K, Chi KN. Abiraterone in Metastatic Prostate Cancer. N Engl J Med. 2017; 377:1697-98. https://doi. org/10.1056/NEJMoa1704174.

11. Wang Y, Ray AM, Johnson EK, Zuhlke KA, Cooney KA, Lange EM. Evidence for an association between prostate cancer and chromosome 8q24 and 10q11 genetic variants in African American men: the Flint Men's Health Study. Prostate. 2011; 71:225-31. https://doi.org/10.1002/ pros.21234.

12. Yang M, Xie W, Mostaghel E, Nakabayashi M, Werner L, Sun T, Pomerantz M, Freedman M, Ross R, Regan M, Sharifi N, Figg WD, Balk S, et al. SLCO2B1 and SLCO1B3 may determine time to progression for patients receiving androgen deprivation therapy for prostate cancer. J Clin Oncol. 2011; 29:2565-73. https://doi.org/10.1200/ JCO.2010.31.2405

13. Fujimoto N, Kubo T, Inatomi H, Bui HT, Shiota M, Sho T, Matsumoto T. Polymorphisms of the androgen transporting gene SLCO2B1 may influence the castration resistance of prostate cancer and the racial differences in response to androgen deprivation. Prostate Cancer Prostatic Dis. 2013; 16:336-40. https://doi.org/10.1038/pcan.2013.23.

14. Mostaghel EA, Cho E, Zhang A, Alyamani M, Kaipainen A, Green S, Marck BT, Sharifi N, Wright JL, Gulati R, True LD, Loda M, Matsumoto AM, et al. Association of Tissue Abiraterone Levels and SLCO Genotype with Intraprostatic Steroids and Pathologic Response in Men with High-Risk Localized Prostate Cancer. Clin Cancer Res. 2017; 23:4592-601. https://doi.org/10.1158/10780432.CCR-16-2245.

15. Martin JM, Supiot S, Berthold DR. Pharmacotherapeutic management of locally advanced prostate cancer: current status. Drugs. 2011; 71:1019-41. https://doi. org/10.2165/11591500-000000000-00000.

16. Locke JA, Dal Pra A, Supiot S, Warde P, Bristow RG. Synergistic action of image-guided radiotherapy and androgen deprivation therapy. Nat Rev Urol. 2015; 12:193204. https://doi.org/10.1038/nrurol.2015.50.

17. Binder M, Zhang BY, Hillman DW, Kohli R, Kohli T, Lee A, Kohli M. Common Genetic Variation in CYP17A1 and Response to Abiraterone Acetate in Patients with Metastatic Castration-Resistant Prostate Cancer. Int J Mol Sci. 2016; 17:E1097. https://doi.org/10.3390/ijms17071097.

18. Salvi S, Casadio V, Burgio SL, Conteduca V, Rossi L, Menna C, Carretta E, Costantini M, Zoli W, De Giorgi U. CYP17A1 polymorphisms and clinical outcome of castration-resistant prostate cancer patients treated with abiraterone. Int J Biol Markers. 2016; 31:e264-69. https:// doi.org/10.5301/jbm.5000197.

19. Cho E, Mostaghel EA, Russell KJ, Liao JJ, Konodi MA, Kurland BF, Marck BT, Matsumoto AM, Dalkin BL, Montgomery RB. External beam radiation therapy and abiraterone in men with localized prostate cancer: safety and effect on tissue androgens. Int $\mathrm{J}$ Radiat Oncol Biol Phys. 2015; 92:236-43. https://doi.org/10.1016/j. ijrobp.2015.01.020.

20. Taplin ME, Montgomery B, Logothetis CJ, Bubley GJ, Richie JP, Dalkin BL, Sanda MG, Davis JW, Loda M, True LD, Troncoso P, Ye H, Lis RT, et al. Intense androgendeprivation therapy with abiraterone acetate plus leuprolide acetate in patients with localized high-risk prostate cancer: results of a randomized phase II neoadjuvant study. J Clin Oncol. 2014; 32:3705-15. https://doi.org/10.1200/ JCO.2013.53.4578.

21. Ohnishi T, Ogawa Y, Saibara T, Nishioka A, Kariya S, Fukumoto M, Onishi S, Yoshida S. CYP17 polymorphism as a risk factor of tamoxifen-induced hepatic steatosis in breast cancer patients. Oncol Rep. 2005; 13:485-89.

22. Franke RM, Carducci MA, Rudek MA, Baker SD, Sparreboom A. Castration-dependent pharmacokinetics of docetaxel in patients with prostate cancer. J Clin Oncol. 2010; 28:4562-67. https://doi.org/10.1200/ JCO.2010.30.7025. 
23. Rubin P, Johnston CJ, Williams JP, McDonald S, Finkelstein $\mathrm{JN}$. A perpetual cascade of cytokines postirradiation leads to pulmonary fibrosis. Int J Radiat Oncol Biol Phys. 1995; 33:99-109. https://doi.org/10.1016/0360-3016(95)00095-G.

24. McDonald TL, Hung AY, Thomas CR, Wood LJ. Localized External Beam Radiation Therapy (EBRT) to the Pelvis Induces Systemic IL-1Beta and TNF-Alpha Production: Role of the TNF-Alpha Signaling in EBRT-Induced Fatigue. Radiat Res. 2016; 185:4-12. https://doi.org/10.1667/ RR14072.1.

25. Schwabe RF, Brenner DA. Mechanisms of Liver Injury. I. TNF-alpha-induced liver injury: role of IKK, JNK, and ROS pathways. Am J Physiol Gastrointest Liver Physiol. 2006; 290:G583-89. https://doi.org/10.1152/ajpgi.00422.2005.

26. Christensen E, Pintilie M, Evans KR, Lenarduzzi M, Ménard C, Catton CN, Diamandis EP, Bristow RG. Longitudinal cytokine expression during IMRT for prostate cancer and acute treatment toxicity. Clin Cancer Res. 2009; 15:5576-83. https://doi.org/10.1158/1078-0432. CCR-09-0245.

27. Knight B, Lim R, Yeoh GC, Olynyk JK. Interferongamma exacerbates liver damage, the hepatic progenitor cell response and fibrosis in a mouse model of chronic liver injury. J Hepatol. 2007; 47:826-33. https://doi. org/10.1016/j.jhep.2007.06.022.

28. Sheron N, Bird G, Goka J, Alexander G, Williams R. Elevated plasma interleukin- 6 and increased severity and mortality in alcoholic hepatitis. Clin Exp Immunol. 1991; 84:449-53.

29. Parker WP, Evans JD, Stish BJ, Park SS, Olivier K, Choo R, Nathan MA, Welch BT, Karnes RJ, Mynderse LA, Pisansky TM, Kwon ED, Lowe VJ, Davis BJ. Patterns of Recurrence After Postprostatectomy Fossa Radiation Therapy Identified by C-11 Choline Positron Emission Tomography/Computed Tomography. Int J Radiat Oncol Biol Phys. 2017; 97:52635. https://doi.org/10.1016/j.ijrobp.2016.11.014.

30. Michalski JM, Lawton C, El Naqa I, Ritter M, O'Meara E, Seider MJ, Lee WR, Rosenthal SA, Pisansky T, Catton C, Valicenti RK, Zietman AL, Bosch WR, et al. Development of RTOG consensus guidelines for the definition of the clinical target volume for postoperative conformal radiation therapy for prostate cancer. Int J Radiat Oncol Biol Phys. 2010; 76:361-68. https://doi.org/10.1016/j. ijrobp.2009.02.006. 